\title{
Successful Mechanical Thrombectomy of Middle Cerebral Artery Occlusion 14 Hours after Stroke Onset
}

\author{
Robin Bhattarai ${ }^{1}$, Karuna Tamrakar Karki ${ }^{1}$, Dinesh Kumar Thapa ${ }^{1}$, Navin Kumar Yadav ${ }^{1}$ \\ ${ }^{1}$ Department of Neurosurgery, B \& C Medical College Teaching Hospital \& Research Centre Pvt. Ltd., \\ Birtamode, Nepal
}

\author{
Correspondence: \\ Dr. Robin Bhattarai MS, PhD \\ Endovascular Neurosurgeon \\ Department of Neurosurgery \\ B \& C Medical College Teaching Hospital \& Research Centre Pvt. Ltd. \\ Kankai Rd, Birtamode 57204, state No-1, Jhapa, Nepal \\ Email: robinbhattarai@hotmail.com
}

\begin{abstract}
A 45-year-old patient with no significant past medical history presented to out-patient department with aphasia and right hand weakness with a National Institutes of Health Stroke Scale (NIHSS) of 10 and occlusion of the left middle cerebral artery (MCA) in the M1 segment. Last known normal time was $14 \mathrm{hrs}$ (wake up stroke). Immediate endovascular thrombectomy was performed 14 hours after symptom onset with complete recanalization and complete clinical recovery. Although mechanical thrombectomy is generally considered an effective alternative strategy up to 8 hours after stroke onset, selected patients with a large diffusion/perfusion mismatch and small infarct cores may benefit from an expanded therapeutic window.
\end{abstract}

Key words: Aphasia, Endovascular, Ischemic Stroke, Thrombectomy, Weakness

A cute ischemic stroke is a common cause of disability and death in developed countries. The standard treatment is intravenous thrombolysis for patients presenting within 4.5 hours form the onset of symptoms if the contraindications such as oral anticoagulants, cancer or recent surgery are excluded. ${ }^{1-3}$ In addition, mechanical recanalization is a promising new treatment option for patients with occlusion of major cerebral arteries as a cause of ischemic stroke. It is often used in addition to intravenous thrombolysis ("bridging concept"). ${ }^{4-6}$

For two decades, intravenous thrombolysis (IVT) has been the most important treatment for patients with acute ischemic stroke. ${ }^{7}$ However, due to the narrow time window of 4.5 hours after the onset of symptoms, the rapid decline of curative effect, and various contraindications, such as comorbidity, oral anticoagulation or recent surgery, the qualification of IVT is limited. In addition, the recanalization rate and prognosis of patients with large

42

Date submitted: 02/ 01/2021

Date accepted: 19/01/2021 thrombosis and proximal vascular occlusion after IVT are poor. ${ }^{8}$

Recently, data from several randomized clinical trials show that endovascular therapy has obvious benefits for patients with acute ischemic stroke caused by proximal anterior circulation occlusion. 9. In all these trials, imaging based patient selection, especially for diffusion / perfusion mismatch and exclusion of patients with large infarct core, has been proved to be successful in avoiding ineffective interventions. ${ }^{10}$

At present, the time window of good curative effect after endovascular treatment is not clear. It is suggested that endovascular retriever thrombectomy should be performed within 8 hours after symptom onset. ${ }^{11}$

Here, we describe a patient with a Left hemispheric ischemic syndrome who presented late for systemic thrombolysis. He was then treated with mechanical recanalization. 


\section{Case Presentation}

A 45-year old, right-handed previously healthy male patient presented with an acute right sided weakness and facial palsy to a peripheral hospital (NIHSS on admission: 2). Computed tomography (CT) angiography 12 hours and 20 minutes after symptom onset showed an occlusion of the left MCA in the M1 segment with a large perfusion deficit in the complete MCA territory. He was transferred immediately to the Angio-suite for Digital subtraction angiography (DSA). 4-vessel DSA was performed. The subsequent cerebral distraction angiography (DSA) confirmed the complete occlusion of left MCA in the M1 segment (Figure 1).

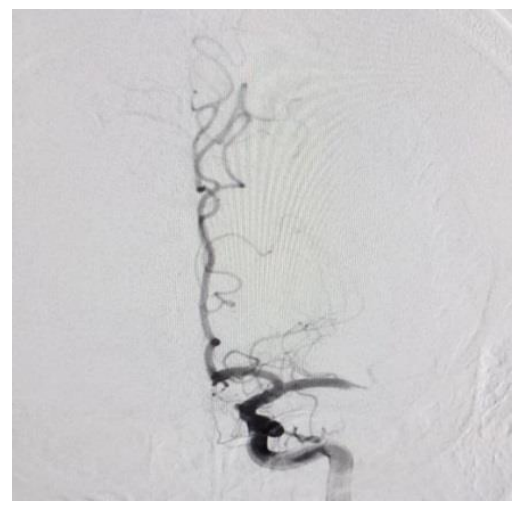

Figure 1: Digital subtraction angiography showing occlusion of M1 segment of Left middle cerebral artery

After consent of the family we performed mechanical thrombectomy in conscious sedation. Complete recanalization was achieved with the ACE 68 aspiration catheter and micro catheter in two attempt 14 hours after stroke onset. We also administered intra-arterial Tenecteplase. Angiography at the end of the intervention showed a complete reperfusion of the former occluded left MCA territory (TICI classification 3) (Figure 2).

egneuro Volume 03, Issue 01, 2021

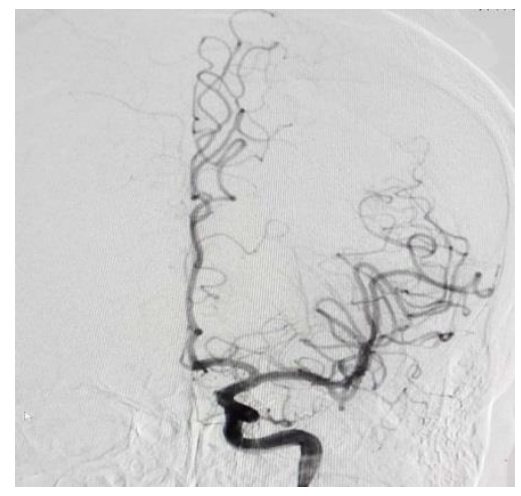

Figure 2: Digital subtraction angiography showing complete recanalization of M1 segment of Left middle cerebral artery

NIHSS immediately after the intervention was 4, and on the following day 2 with a mild dysarthria. The patient was transferred to HDU and was kept in observation for $24 \mathrm{hrs}$ and was transferred to Neuro ward (Figure 3). One week after symptom onset the patient reported to have completely recovered.

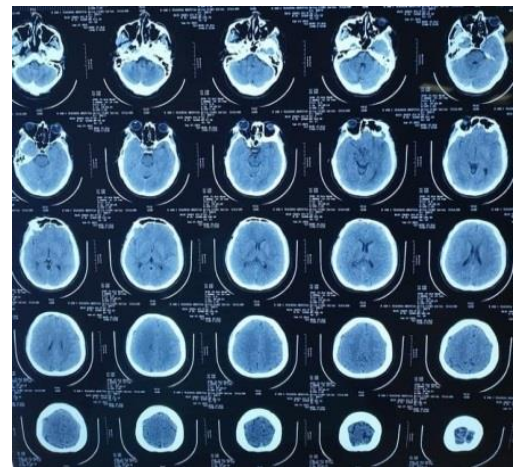

Figure 2: Computed Tomography 8 hours post procedure.

\section{Discussion}

Endovascular therapy can improve the functional outcome of patients with acute stroke with large vessel occlusion in anterior circulation. ${ }^{12}$ Recanalization is associated with better prognosis, and the recanalization rate of mechanical technique has been proved to be better than that of drug therapy alone. ${ }^{12}$ Patients with mild or rapidly improving symptoms, but proximal vascular occlusion, if not treated, the prognosis is very poor. ${ }^{12}$ In early studies, especially proximal vascular occlusion and NIHSS $\geq 10$ were predictors of poor prognosis in stroke patients with mild or rapidly improving symptoms. ${ }^{13}$ Therefore, rapid identification and treatment of these patients is of 
great significance. In case of large vessel occlusion and low NIHSS with decision against treatment in the acute phase, it is strongly recommended to transfer the patient to stroke centers with endovascular treatment facilities for further monitoring.

However, the time window for good results after endovascular therapy is not clear. At the third European Stroke Organization Conference in Prague, the first results of the dawn study have just been presented, but not yet fully published. The results show that the removal of thrombus by endovascular thrombectomy within 24 hours after the appearance of symptoms and signs can reduce the disability of some stroke patients, such as wake-up stroke. ${ }^{14}$ As demonstrated by flint et al and earlier by Jovin et al, endovascular treatment with stent retriever thrombectomy within 8 hours after symptom onset is safe and can reduce the severity of post-stroke disability. ${ }^{11,15}$

Multimodal MRI imaging techniques has been shown to better identify patients who may benefit from endovascular reperfusion therapy. Especially in patients with obvious perfusion / diffusion mismatch on MRI, there are large areas of salvable brain tissues, which can be recovered from ischemia after reperfusion by endovascular treatment, showing better long-term clinical results. $^{10}$

\section{Conclusion:}

Although mechanical thrombus extraction is usually an alternative strategy for acute revascularization within 8 hours after stroke onset $^{11,15}$, selected patients may benefit from an expanded treatment window.

\section{References:}

1. G. DeVeber and F. Kirkham, "Guidelines for the treatment and prevention of stroke in children," The Lancet Neurology, vol. 7, no. 11, pp. 983-985, 2008.View at: Publisher Site | Google Scholar

2. E. S. Roach, M. R. Golomb, R. Adams et al., "Management of stroke in infants and children," Stroke, vol. 39, pp. 2644-2691, 2008.View at: Publisher Site | Google Scholar

3. P. Monagle, A. K. C. Chan, N. Goldenberg et al., "Antithrombotic therapy in neonates and children," Chest, vol. 141, no. 2, pp. e737S-e801S, 2012.View at: Publisher Site | Google Scholar

egneuro Volume 03, Issue 01, 2021
4. M. J. Ellis, C. Amlie-Lefond, and D. Orbach, "Endovascular therapy in children with acute ischemic stroke," Neurology, vol. 79, no. 13, pp. S158-S164, 2012.View at: Publisher Site | Google Scholar

5. T. R. Ladner, L. He, L. C. Jordan, C. Cooper, M. T. Froehler, and J. Mocco, "Mechanical thrombectomy for acute stroke in childhood: how much does restricted diffusion matter?" BMJ Case Reports, vol. 2014, 2014.View at: Publisher Site | Google Scholar

6. V. Huded, V. Kamath, B. Chauhan et al., "Mechanical thrombectomy using solitaire in a 6-year-old child," Journal of Vascular and Interventional Neurology, vol. 8, no. 2, pp. 13-16, 2015. View at: Google Scholar

7. W. Hacke, M. Kaste, E. Bluhmki et al., "Thrombolysis with alteplase 3 to 4.5 hours after acute ischemic stroke," The New England Journal of Medicine, vol. 359, no. 13, pp. 1317-1329, 2008.View at: Publisher Site | Google Scholar

8. C. H. Riedel, P. Zimmermann, U. Jensen-Kondering, R. Stingele, G. Deuschl, and O. Jansen, "The importance of size: successful recanalization by intravenous thrombolysis in acute anterior stroke depends on thrombus length," Stroke, vol. 42, no. 6, pp. 1775-1777, 2011.View at: Publisher Site | Google Scholar

9. M. Goyal, B. K. Menon, W. H. van Zwam et al., "Endovascular thrombectomy after large-vessel ischaemic stroke: a meta-analysis of individual patient data from five randomised trials," The Lancet (London, England), vol. 387, no. 10029, pp. 1723-1731, 2016.View at: Publisher Site | Google Scholar

10. M. G. Lansberg, M. Straka, S. Kemp et al., "MRI profile and response to endovascular reperfusion after stroke (DEFUSE 2): a prospective cohort study," The Lancet Neurology, vol. 11, no. 10, pp. 860-867, 2012.View at: Publisher Site | Google Scholar

11. T. G. Jovin, A. Chamorro, E. Cobo et al., "Thrombectomy within 8 hours after symptom onset in ischemic stroke," The New England Journal of Medicine, vol. 372, no. 24, pp. 2296-2306, 2015.View at: Publisher Site | Google Scholar

12. N. Wahlgren, T. Moreira, P. Michel et al., "Mechanical thrombectomy in acute ischemic stroke: consensus statement by ESO-karolinska stroke update 2014/2015, supported by ESO, ESMINT, ESNR and EAN," International Journal of Stroke, vol. 11, no. 1, pp. 134-147, 2016.View at: Publisher Site | Google Scholar

13. K. Nedeltchev, B. Schwegler, T. Haefeli et al., "Outcome of stroke with mild or rapidly improving symptoms," Stroke, vol. 38, no. 9, pp. 2531-2535, 2007.View at: Publisher Site | Google Scholar

14. T. G. Jovin and R. G. Nogueira for the DAWN investigators, "Dawn in full daylight (DWI or CTP Assessment with clinical mismatch in the triage of wake up and late presenting strokes undergoing neurointervention)," 2017. View at: Google Scholar

15. A. C. Flint, G. R. Duckwiler, R. F. Budzik, D. S. Liebeskind, and W. S. Smith, "Mechanical thrombectomy of intracranial internal carotid occlusion: pooled results of the MERCI and multi MERCI part I trials," Stroke, vol. 38, no. 4, pp. 1274-1280, 2007.View at: Publisher Site | Google Scholar 